\title{
Antibacterial and Zebrafish-based Screening for Wnt Signal Inhibitory Activities of Syzygium polycephaloides (C.B. Robb. Merr.) Bark Extracts
}

Gio Martin A. Ocfemia ${ }^{1}$, Galileo Gregory Abrasaldo ${ }^{1}$, Ramon Carmelo A. Fabile ${ }^{1}$ and Rolly G. Fuentes ${ }^{1^{*}}$

${ }^{1}$ Division of Natural Sciences and Mathematics, University of the Philippines Visayas Tacloban College, 6500 Tacloban

City, Philippines

\begin{abstract}
Syzygium polycephaloides, a plant native to Southeast Asia, is used to cure common illnesses. In this study, the methanolic bark extracts of $S$. polycephaloides was evaluated for their antibacterial activity and screened for their Wnt signal inhibitory activity using zebrafish-based assay. In the antibacterial assay, the extracts were tested against Staphylococcus aureus, Bacillus subtilis, Pseudomonas aeroginosa, and Escherichia coli using disk diffusion assay. On the other hand, zebrafish-based screening was used to determine the inhibitory potential of $S$. polycephaloides against the Wnt signal. Zebrafish embryos were treated with $\mathrm{LiCl}$ to upregulate the Wnt signal which produces eyeless phenotype. The methanolic extracts had antibacterial activity against the test microorganisms except $P$. aeruginosa. After fractionation, ethyl acetate (EtOAc) and aqueous fractions exhibited wide-spectrum antibacterial activity. For the Wnt signal inhibitory activity screening, the LiCl-treated embryos were rescued to their normal eye development after treatment with the $S$. polycephaloides bark extracts $(100 \mu \mathrm{g} / \mathrm{mL})$. The results suggest that the extracts may have inhibited the Wnt signal. This study shows that the $S$. polycephaloides is a potent source of antibacterial compounds and Wnt inhibitors.
\end{abstract}

Keywords: disk-diffusion assay; lithium chloride; XAV939

\section{INTRODUCTION}

Syzigium polycephaloides, which belongs to the family Myrtaceae, is utilized by locals in the Philippines as a cure for common illnesses such as cough and hypertension, and a source of local tropical wine (Taguiling, 2013; Environmental Research and Development Bureau, 2017). The fruit is a good source of natural antioxidant because of its high flavonoid and flavonol content (Santiago et al., 2007). Its seeds contain the compound syzygiol which exhibited inhibition of skin tumor promotion (Nishizawa et al., 1991). Other species of the genus Syzigium, particularly $S$. cumini and $S$. antisepticum, are known to possess antioxidant, antidiabetic and antimicrobial properties (Srivastava \& Chandra, 2013; Yuan \& Yuk 2018).

There is a current crisis on antimicrobial resistance because of misuse, inappropriate prescribing, extensive agricultural use and availability of few antibiotics (Ventola, 2015). This scenario persists as a global threat, with an annual increase in the Philippines reported strains of antimicrobial resistant microorganisms (Research Institute for Tropical Medicine, 2018). Thus, searching for novel antibiotics and new source of these antibiotics must be undertaken. Plants are still considered as very important resources for drug discovery particularly as an alternative source of antimicrobial agents (Khameneh et al., 2019). A single plant may contain many compounds of interest. There are more than 1000 different phytochemicals isolated and identified from plants which possess antimicrobial activities against human pathogens (Barbieri et al., 2017). These isolated compounds can be considered good leads in drug development. To the best of our knowledge, there are 
limited studies on the biological activities of polycephaloides.

The evolutionary conserved Wnt/ $\beta$-catenin signaling pathway is involved in stem cell renewal, cell proliferation and tissue homeostasis (Steinhart \& Angers, 2018). Aberrant regulations caused by mutations in the Wnt pathway have been implicated in various diseases such as sebaceous skin tumour, type II diabetes, bone density defects and colorectal cancers (Nusse \& Clevers, 2017; Zhan et al., 2017). Targetting the Wnt signal pathway has been considered as potential therapeutic strategy against cancer (Anastas \& Moon, 2013). Natural compounds in some medicinal plants have been reported to be natural agonists and inhibitors of the Wnt pathway which make them good possibilities for creating treatments that can combat cancer (Fuentes et al., 2015a). Natural compounds such as the cardenolides (Park et al., 2014) and limonoids (Fuentes et al., 2015b) have been recently identified to be potential modulators of the Wnt pathway. In this study, methanolic bark extracts of S. polycephaloides were screened for their antibacterial and Wnt signal inhibitory activities.

\section{MATERIALS AND METHOD}

\section{A. Plant Samples}

The bark samples were carefully extracted from a large Igot tree (Syzygium polycephaloides [C.B. Robb.] Merr.) from Brgy. Lusad, Burauen, Leyte, Philippines on September 2018. The tree was confirmed in its identification by the head forester in the Department of Environment and Natural Resources Regional Office 8, Tacloban City, Philippines. Collected bark were air-dried in a net bag, safely contained at room temperature at the UPV Tacloban College.

\section{B. Extraction}

The bark sample (100.6 g) was pulverized using a blender and macerated with $750 \mathrm{~mL}$ 100\% methanol (MeOH). The mixture was left overnight and filtered with cheesecloth and Whatman No. 1 filter paper. Then maceration was conducted again to the residue with $750 \mathrm{~mL}$ 100\% methanol. The solvent was removed under reduced pressure at $35{ }^{\circ} \mathrm{C}$ (BUCHI Rotavapor R-270) which constitute the crude methanolic extract (5.0 g). Crude methanolic extract $(1.01 \mathrm{~g})$ was resuspended in $30 \mathrm{~mL}$ of $10 \%$ methanol and extracted with $n$-hexane $(3 \times 30 \mathrm{~mL})$ to give 29.3 mg of $n$-hexane extract. The $\mathrm{MeOH}$ layer was extracted with
EtOAC $(3 \times 30 \mathrm{~mL})$ to give the EtOAc extract $(47.5 \mathrm{mg})$. The remaining layer was dried in-vacuo and constitute the aqueous layer (933.4 mg). Extracts were stored in refrigerator until analysis.

\section{Test microorganisms}

All test microorganisms were obtained from Department of Science and Technology (DOST)- Region 8, Palo, Leyte, Philippines. Staphylococcus aureus (ATCC 25923), Bacillus cereus (ATCC 10876), Pseudomonas aeruginosa (ATCC 27853), and Escherichia coli (ATCC 25922) were maintained at Nutrient Agar slants and stored at $4^{\circ} \mathrm{C}$.

\section{Disk Diffusion Assay}

The crude methanolic extract and the solvent fractions were tested for their antibacterial activity against Escherichia coli, Staphylococcus aureus, Pseudomonas aeroginosa, and Bacillus subtilis with the disk diffusion method outlined by the Clinical Laboratory Standards Institute (2009a). Day-old bacterial suspensions were prepared and standardized using 0.5 McFarland Standard to contain approximately 1.5 x 108 colony-forming units (CFU)/mL. Using sterile cotton-swabs, the bacteria were inoculated on the surface of Mueller-Hinton Agar (MHA) and the inoculum was incubated for 5-10 min. Sterile test disks (5 mm diameter, Whatman no.1) impregnated with $10 \mu \mathrm{g} / \mathrm{mL}$ in $10 \%$ DMSO of the plant extracts. Positive and negative control disks were eluted with $10 \mu \mathrm{g} / \mathrm{mL}$ streptomycin and 10\% DMSO respectively. All plates were incubated at room temperature for $24 \mathrm{~h}$. The resulting zones of inhibition (ZOI) was digitally measured using ImageJ analysis software (Schneider et al., 2012).

\section{Minimum Inhibitory Concentration (MIC) Determination}

The minimum inhibitory concentration (MIC) was determined by the two-fold microdilution method recommended by the Clinical Laboratory Standards Institute (2009b). Microdilutions of active extracts were tested at concentrations from $10 \mathrm{mg} / \mathrm{mL}$ halving down six times to reach the lowest concentration of $0.313 \mathrm{mg} / \mathrm{mL}$. Bacterial suspensions of E. coli, S. aureus, P. aeroginosa, and $B$. subtilis were prepared and the turbidity was adjusted 
by comparison with $0.5 \mathrm{McFarland}$ standard. In a 96-well plate, $50 \mu \mathrm{L}$ of bacterial suspension was treated with the control and extracts. The MIC is the lowest concentration of the extract which inhibited the visible growth of the microorganism.

\section{E. Zebrafish Maintenance and Embryo Collection}

Wild-type zebrafish (Danio rerio) were purchased from a local fish dealer in Tacloban City, Philippines. Male and female zebrafish were placed in separate $7 \mathrm{~L}$ fish tanks equipped with aerators (Reed \& Jennings, 2011). The zebrafish were maintained in a $14 \mathrm{~h}$ light and $10 \mathrm{~h}$ dark cycle under an optimal temperature range of 27 to $28.5^{\circ} \mathrm{C}$. The zebrafish were fed twice a day, once in the morning and once in the afternoon, using pond flakes, and acclimatized for 2 to 3 months. To induce spawning, a pair of mature male and female zebrafish were placed in a mating tank ( 2 males: 1 female), while being separated from each other using a horizontal tank divider. The dividers were removed on the onset of sunrise in the following day, and the zebrafish were left for $1 \mathrm{~h}$ and $30 \mathrm{~min}$. Embryos were collected using a plastic pipette and were placed in petri dishes with distilled water.

\section{F. Zebrafish-based Assay}

Small molecule screening methods were based on the procedure by Robertson et al. (2014). The collected embryos at mid-blastula stage were transferred to a mesh basket to commence the transfer between solutions. Embryos at exactly 4.5 hours post-fertilization (hpf) were immersed in $375 \mathrm{mM}$ $\mathrm{LiCl}$ (Unilab) at room temperature for exactly $10 \mathrm{~min}$ and were agitated at every minute. Embryos were washed for 20 seconds, three consecutive times, using room temperature distilled water and were incubated at $28.5^{\circ} \mathrm{C}$ for $15 \mathrm{~min}$. Necrotic embryos were removed and ten embryos were placed in each well of a 24-well plate. Lithium-treated embryos were then treated with 50 and $100 \mu \mathrm{g} / \mathrm{mL}$ in $1 \%$ DMSO and $5 \mu \mathrm{M}$ XAV939. Embryos were incubated at $28.5^{\circ} \mathrm{C}$ and were observed for rescue of $\mathrm{LiCl}$-induced eyeless phenotype at prim-5 stage (24 hpf). Developmental defects and deaths were noted and scored at long-pec stage (48 hpf).

\section{G. Data Analysis}

All tests were carried out in three replications. The results are expressed as mean \pm standard deviation $(n=3)$.

\section{RESULT AND DISCUSSION}

Plant extracts obtained from species of the genus Syzygium contain documented pharmacological properties (Srivastava \& Chandra, 2013; Yuan \& Yuk 2018). Syzygium polycephaloides which is native to the Indo-Pacific, has little literature characterizing its bioactivity. In this study, $S$. polycephaloides bark extract was evaluated for its potential as source of antibacterials and Wnt signal inhibitors.

The crude methanolic extract showed significant inhibitory activity against all the test bacteria except $P$. aeruginosa. But after fractionation, only the EtOAc and aqueous fractions exhibited wide-spectrum of antibacterial property. The EtOAc fraction has zone of inhibitions ranging from 8.4 to $9.7 \mathrm{~mm}$ while the aqueous fraction from 7.7 to $9.3 \mathrm{~mm}$ (Table 1 ).

Table 1. Mean zone of inhibition of the different test bacteria treated with the bark extracts of S. polycephaloides

\begin{tabular}{|c|c|c|c|c|}
\hline \multirow{3}{*}{ Extracts $^{\mathbf{a}}$} & \multicolumn{4}{|c|}{ Zone of Inhibition (mm) } \\
\hline & \multicolumn{2}{|c|}{ Gram positive } & \multicolumn{2}{|c|}{ Gram Negative } \\
\hline & B. subtilis & S. aureus & E. coli & P. aeroginosa \\
\hline Streptomycin $^{*}$ & $23.7 \pm 1.8$ & $22.4 \pm 4.1$ & $19.8 \pm 2.9$ & $21.0 \pm 2.1$ \\
\hline 10\% DMSO & $--^{+}$ & $--^{\dagger}$ & $-{ }^{\dagger}$ & $-{ }^{\dagger}$ \\
\hline Crude extract & $8.4 \pm 0.20$ & $8.4 \pm 0.5$ & $8.2 \pm 0.7$ & $-{ }^{\dagger}$ \\
\hline Hexane & $7.8 \pm 0.3$ & $8.4 \pm 0.6$ & $9.0 \pm 0.4$ & $--^{\dagger}$ \\
\hline EtOAc & $9.7 \pm 1.1$ & $9.4 \pm 1.1$ & $8.4 \pm 0.6$ & $8.4 \pm 0.4$ \\
\hline Aqueous & $7.7 \pm 0.4$ & $8.9 \pm 0.8$ & $9.3 \pm 0.6$ & $8.6 \pm 0.7$ \\
\hline
\end{tabular}


The data also show that antibacterial activity of the $S . \pm 0.90 \mathrm{mg} / \mathrm{mL}$ ) (Djipa et al., 2000). S. cumini leaf ethanolic polycephaloides bark extracts are within the range of MIC as extract shows much lower MIC values at $200 \mu \mathrm{g} / \mathrm{mL}$ for $E$. compared to bark and leaf extracts of other Syzygium species (Table 2). It has similar MIC values with the aqueous crude coli, $90 \mu \mathrm{g} / \mathrm{mL}$ for $P$. aeruginosa, and $200 \mu \mathrm{g} / \mathrm{ml}$ for $\mathrm{S}$. extract of Syzygium jambos bark at $0.5-1.0 \mathrm{mg} / \mathrm{mL}$ for $S$. polycephaloides crude extract, EtOAc and aqueous are aureus (compared to $2.50 \pm 0.00 \mathrm{mg} / \mathrm{mL}-$ S. polycephaloides), comparable.

but similar values at $>1.0 \mathrm{mg} / \mathrm{mL}$ for $E$. coli (compared to 1.88

Table 2. Minimum inhibitory concentration (MIC) of the $S$. polycephaloides extracts against the tested bacteria

\section{$\mathrm{MIC}^{\mathrm{a}}(\mathrm{mg} / \mathrm{mL})$}

\begin{tabular}{|c|c|c|c|c|}
\hline \multirow{2}{*}{ Extracts } & \multicolumn{2}{|c|}{ Gram positive } & \multicolumn{2}{|c|}{ Gram negative } \\
\hline & B. subtilis & S. aureus & E. coli & P. aeruginosa \\
\hline Crude Extract & $1.56 \pm 1.30$ & $1.88 \pm 0.90$ & $1.88 \pm 0.90$ & $\mathrm{~N} / \mathrm{A}^{\dagger}$ \\
\hline Hexane & $10.00 \pm 0.00$ & $5.00 \pm 0.00$ & $7 \cdot 50 \pm 3.50$ & $\mathrm{~N} / \mathrm{A}^{\dagger}$ \\
\hline Ethyl Acetate & $2.50 \pm 0.00$ & $2.50 \pm 0.00$ & $1.88 \pm 0.90$ & $10.00 \pm 0.00$ \\
\hline Aqueous & $1.88 \pm 0.90$ & $2.50 \pm 0.00$ & $1.88 \pm 0.90$ & $7 \cdot 50 \pm 3.50$ \\
\hline
\end{tabular}

a: Values are presented as mean \pm SD. $n=2$.

${ }^{\dagger}$ : not applicable; No tests were conducted due to absence of ZOI on disk diffusion assay.

It can be said that fractionation did not enhance activity except that EtOAc and aqueous fractions exhibited antibacterial activity against $P$. aeruginosa as compared to the crude extract. The $n$-hexane fractions which comprise a very small part of the crude extract had higher MIC values. The results suggest that slightly polar to polar compounds are responsible for the antibacterial activities of the extracts. Phytochemical screening of the extract showed that the methanolic extract, ethyl acetate and aqueous fractions tested positive for the presence of phenols, flavonoids, and saponins. Phenolic compounds including flavonoids showed diverse mechanism of action against bacteria which include inhibition of the efflux pump, damaging the cell membrane and inhibition of cell wall biosynthesis (Khameneh et al., 2019).

Treatment of zebrafish embryos with $\mathrm{LiCl}$ during the transition from dome stage $-30 \%$ epiboly at $4.5 \mathrm{hpf}$ resulted in eyeless phenotype. $\mathrm{LiCl}$ chloride is a known Wnt activator since it inhibits $\mathrm{GSK}_{3} \beta$ activity and mimics mutations found in colorectal cancers (Robertson et al., 2014). Wnt pathway activation in zebrafish is expressed through an eyeless phenotype (Nishiya et al., 2014). Hence, finding inhibitors of the pathway by rescuing zebrafish from a lithium chlorideinduced eyeless phenotype can show potentially excellent therapeutic agents. In this study, XAV939, a known Wnt signal inhibitor was used as the positive control (Robertson et al., 2014). Embryos exposed to XAV939 showed $97 \%$ of eye recovery with no recorded mortality, but all exhibited defects such as heart edema (Figure 2). S. polycephaloides bark extracts exhibited eye-recovery (including with observed defects) though only at $25.6 \pm 5.1 \%$ because the bark extracts also exhibited considerable mortality (35.6 \pm $5.1 \%)$.

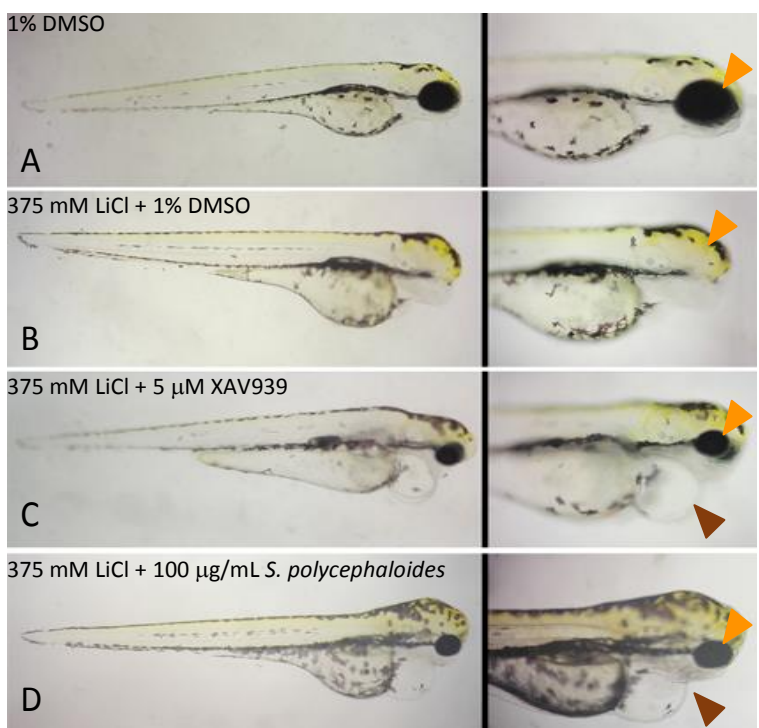

Figure 1. Phenotype of Danio rerio embryos observed at 72 hpf after treatment of 1\% DMSO (A, control), $375 \mathrm{mM} \mathrm{LiCl}$ 
(B, activation of Wnt signal). Figures 1.C and 1.D presents the phenotype after treatment of LiCl-treated embryo with $5 \mu \mathrm{M}$

XAV939 (C, positive control) and $100 \mu \mathrm{g} / \mathrm{mL} S$.

polycephaloides bark extract (D). Orange arrow indicates eye part while brown arrow indicates developmental defects such heart edema.

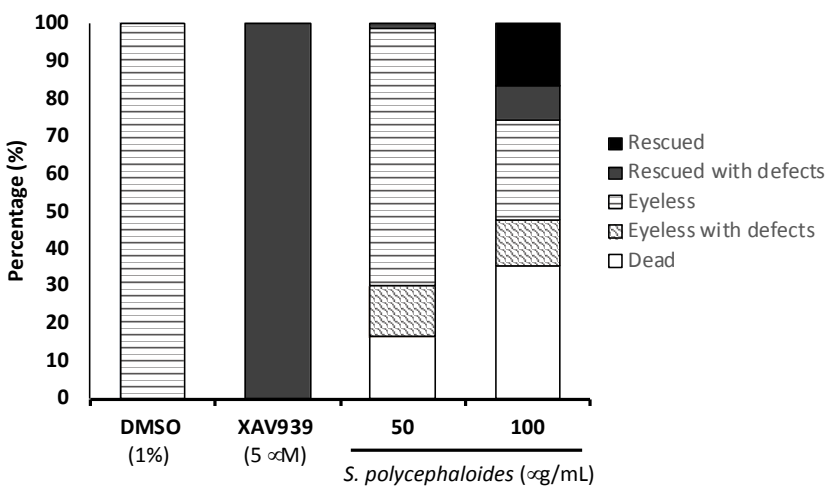

Figure 2. Comparison of observed rescued eye-recoveries, mortality, and defects among LiCl-treated D. rerio embryos exposed to 1\% DMSO; XAV939 (PC), and and $S$.

polycephaloides bark, after $48 \mathrm{hpf}(\mathrm{n}=3)$. Each replicate has 30 embryos.

But still, the results suggest that $S$. polycephaloides can be a potent source of Wnt inhibitors. Further studies on the isolation of its active compound must be conducted to eliminate the other compounds which have caused high mortality in the zebrafish embryos. As presented earlier, the methanolic crude extract contains phenolic and flavonoid compounds which may be responsible for the inhibitory activity against the Wnt signal of the plant. Quercetin, galangin, apeginin and naringenin are some of the flavonoids reported to inhibit the Wnt signal and exhibited antiproliferative activities against cancer cell lines with active Wnt signal (Fuentes et al., 2015a). To the best of our knowledge, there are no studies on the isolation of compounds present in the bark of $S$. polycephaloides.

\section{CONCLUSION}

In conclusion, the methanolic bark extract of S. polycephaloides possess antibacterial properties. A widespectrum activity is observed for ethyl acetate and aqueous fractions. Wnt signal inhibitory activity was also exhibited as observed by the rescue of eye-development in embryos with upregulated Wnt signal. Further studies on the isolation and characterization of the active compounds are needed to establish the pharmacological importance of $S$. polycephaloides.

\section{ACKNOWLEDEGEMENT}

This research project was funded by the Regular In-House Research Grant of the Office of the Vice-Chancellor for Research and Extension, University of the Philippines Visayas.

\section{REFERENCES}

Anastas, JN \& Moon, RT 2013, 'WNT signalling pathways as therapeutic targets in cancer', Nature Reviews Cancer, vol. 13, no. 1, pp. 11-26.

Barbieri, R, Coppo, E, Marchese, A, Daglia, M, SobarzoSánchez, E, Nabavi, SF \& Nabavi, S Md 2017, 'Phytochemicals for human disease: an update on plant-derived compounds antibacterial activity', Microbiological Research, vol. 196, pp. 44-68.

Clinical and Laboratory Standards Institute 2009a, Methods for dilution antimicrobial susceptibility tests for bacteria that grow aerobically; approved standard, 8th edn, CLSI document Mo7-A8, Clinical and Laboratory Standards Institute, Wayne, PA.

Clinical and Laboratory Standards Institute 2009b,
Performance standards for antimicrobial disk susceptibility tests; approved standard, 10th edn, CLSI document Mo2-A10, Clinical and Laboratory Standards Institute, Wayne, PA.

de Oliveira, GF, Furtado, NAJC, Filho, AA dS, Martins, CHGM, Bastos, JK, Cunha, WR \& de Silva, ML dA 2007, 'Antimicrobial activity of Syzygium cumini (Myrtaceae) leaves extract', Brazilian Journal of Microbiology, vol. 38, no. 2, pp. 381-384.

Djipa, CD, Delmée, M \& Quetin-Leclercq, J 2000, 'Antimicrobial activity of bark extracts of Syzygium jambos (L.) Alston (Myrtaceae), Journal of Ethnopharmacology, vol. 71, no. 1-2, pp. 307-313. 
Syzygium polycephaloides (C.B. Robb) Merr. Research Information Series on Ecosystems (RISE) 2017, 29(2). ERDB, College, Laguna, Philippines.

Fuentes, RG, Arai, MA \& Ishibashi, M 2015, 'Natural compounds with Wnt signal modulating activity', Natural Product Reports, vol. 32, no. 12, pp. 1622-1628.

Fuentes, RG, Toume, K, Arai, MA, Sadhu, SK, Ahmed, F \& Ishibashi, M 2015, 'Limonoids with Wnt signal inhibitory activity isolated from the fruits of Azadirachta excelsa', Phytochemistry Letters, vol. 11, pp. 280-285.

Khameneh, B, Iranshahy, M, Soheili, V \& Bazzaz, BSF 2019, 'Review on plant antimicrobials: a mechanistic viewpoint', Antimicrobial Resistance and Infection Control, vol. 8, no. 118. doi: 10.1186/s13756-019-0559-6.

Nishiya, N, Oku, Y, Kumagai, Y, Sato, Y, Yamaguchi, E, Sasaki,

A, Shoji, M, Ohnishi, Y, Okamoto, H \& Uehara, Y 2014, 'A zebrafish chemical suppressor screening identifies small molecule inhibitors of the Wnt/ $\beta$-catenin pathway', Chemistry \& Biology, vol. 21, no. 4, pp. 530-531.

Nishizawa, M, Yamada, H, Samo, J, Shô, I, Yugi, H, Hiroshi, I, Chairul, MS \& Harukuni, T 1991, 'Structure of syzygiol: a skin-tumor promotion inhibitor', Tetrahedron Letters, vol. 32, pp. 211-212.

Nusse, R \& Clevers, H 2017, 'Wnt/ $\beta$-catenin signaling, disease, and emerging therapeutic modalities', Cell, vol. 169, no. 6, pp. 985-999.

Park, HY, Toume, K, Arai, MA, Sadhu, SK, Ahmed, F \& Ishibashi, M 2014, 'Calotropin: a cardenolide from Calotropis gigantea that inhibits Wnt signaling by increasing casein kinase $1 \alpha$ in colon cancer cells', Chembiochem, vol. 15, no. 6 , pp. 872-878.

Reed, B \& Jennings, M 2011, Guidance on the housing and care of zebrafish Danio rerio, Research Animals Department, Science Group, Royal Society for the Prevention of Cruelty to Animals, pp. 7-42.

Research Institute for Tropical Medicine 2019, Antimicrobial Resistance Surveillance Program 2018 Data Summary Report, Department of Health (Philippines), Muntinlupa City, Philippines, pp. 68.

Robertson, J, Danzmann, K, Charles, S, Blake, K, Olivares, A, Bamikole, S, Olson, M \& Van Raay, TJ 2014, 'Targeting the Wnt pathway in zebrafish as a screening method to identify novel therapeutic compounds', Experimental Biology and Medicine, vol. 239, no. 2, pp. 169-170.

Santiago, DM, Garcia, VV, Dizon, EI \& Merca, FE 2007, 'Antioxidant activities, flavonol and flavanol content of selected Southeast Asian indigenous fruits', Philippine
Agricultural Scientist, vol. 90, no. 2, pp. 123-130.

Schneider, CA, Rasband, WS \& Eliceiri, KW 2012, 'NIH Image to ImageJ: 25 years of image analysis', Nature Methods, vol. 9, no. 7 pp. 671-675.

Steinhart, Z \& Angers, S 2018, 'Wnt signaling in development and tissue homeostasis', Development, vol. 145, no. 11. doi: dev146589.

Srivastava, S \& Chandra, D 2013, 'Pharmacological potentials of Syzygium cumini: a review', Journal of the Science of Food and Agriculture, vol. 93, no. 9, pp. 20842093.

Taguiling, NK 2013, 'Macrofloral biodiversity conservation in Ifugao', European Scientific Journal, vol. 4, pp. 469482.

Ventola, CL 2015, 'The antibiotic resistance crisis part 1: causes and threats', Pharmacy \& Therapeutics, vol. 40, no. 4, pp. 277-283.

Yuan, W \& Yuk, HG 2018, 'Antimicrobial efficacy of Syzygium antisepticum plant extract against Staphylococcus aureus and methicillin-resistant $S$. aureus and its application potential with cooked chicken', Food Microbiology, vol. 72, pp. 176-184.

Zhan, T, Rindtorff, N \& Boutros, M 2017, 'Wnt signaling in cancer', Oncogene, vol. 36, no. 11 pp. 1461-1473. 